\title{
A novel absorption spectrometric method, based on graphene nanomaterials, for detection of hepatocellular carcinoma-specific $\mathrm{T}$ lymphocyte cells
}

This article was published in the following Dove Press journal:

International Journal of Nanomedicine

Jianmeng Zhu, ${ }^{1, *}$ Yiping $\mathrm{Li},{ }^{1}, *$ Lei $\mathrm{Li}^{2}{ }^{2}$ Jian Wang,' Hongqin Wang,' Wenzhong Hong,' Ke Hao, ${ }^{3}$ Yadan Xue, ${ }^{3}$ Bingyu Chen, ${ }^{1,3}$ Zhen Wang ${ }^{1,3}$

'Department of Clinical Laboratory, Chun'an First People's Hospital

(Zhejiang Provincial People's Hospital Chun'an Branch), Hangzhou, Zhejiang

Province, China; ${ }^{2}$ Department of Pathophysiology, School of Basic Medical Science, Southern Medical University, Guangzhou, Zhejiang,

China; ${ }^{3}$ Department of Blood

Transfusion, Zhejiang Provincial People's Hospital, People's Hospital of Hangzhou Medical College, Hangzhou, Zhejiang, China

*These authors contributed equally to this work

Correspondence: Bingyu Chen Chun'an First People's Hospital (Zhejiang Provincial People's Hospital Chun'an Branch), I869 Huanhubei Road, Chun'an, Hangzhou 3I I700, Zhejiang, China Tel +86 57I 65035306

Fax +86 57। 65035306

Email chenbingyu@hmc.edu.cn

Zhen Wang

Department of Blood Transfusion,

Zhejiang Provincial People's Hospital, People's Hospital of Hangzhou Medical College, 158 Shangtang Road, Hangzhou 310014 Zhejiang, China

Tel +86 57। 85893270

Fax $+8657 \mid 85893270$

Email wangzhen@hmc.edu.cn
Introduction: Detection of antigen-specific cytotoxic T lymphocytes (CTLs) is the foundation for understanding hepatocellular carcinoma immune pathology and hepatocellular carcinoma immunotherapy. However, the classical method for labeling CTLs, major histocompatibility complex (MHC)-peptide tetramer, has drawbacks and needs further improvement.

Materials and methods: Here, as a new detection probe, a graphene-based MHC-peptide multimer was developed for sensitively and selectively identifying hepatocellular carcinomaspecific T-cells. To assess its detection efficiency, reduced graphene oxide (RGO) was functionalized with hemin and streptavidin to prepare a functionalized HRGO-streptavidin complex. Biotinylated MHC-peptide monomer was subsequently constructed onto HRGO to generate a detection probe for CTL labeling. The number of T-cells was detected through the reaction between HRGO and tetramethylbenzidine.

Results: Using HRGO/MHC-peptide multimers, the number of T-cells was efficiently detected in both the induction system in vitro and in peripheral blood of patients.

Conclusion: HRGO/MHC-peptide multimers methodology has application prospects in the detection of antigen peptide-specific T cells.

Keywords: tetramer, graphene, hemin, major histocompatibility complex multimer, cytotoxic $\mathrm{T}$ lymphocytes, hepatocellular carcinoma

\section{Introduction}

Cytotoxic T lymphocytes (CTLs) play a critical role in vaccine development and immune disease pathology. ${ }^{1}$ The evaluation and analysis of CTL levels contribute to understanding the disease pathology, the mechanism of T-cell immune response, and the application of adoptive immunotherapy. ${ }^{2-4}$ To date, various CTL analytic methods have been developed, such as ${ }^{51} \mathrm{Cr}$ release analysis, cytokine secreted cell counting, T-cell receptor PCR, and major histocompatibility complex (MHC)-peptide (pMHC) tetramer labeling..$^{5-7}$ Among them, tetramer labeling technology is the most common method. Since light bleaching often occurs after the repeated excitation of fluorescent dyes, the stability of the tetramer labeled with organic fluorescent dyes is not reliable..$^{8,9}$ In addition, the affinity between pMHC tetramers and some T-cell receptors on the CTL surface is relatively weak. ${ }^{10}$ Therefore, increasing the number of MHC monomers in the tetramer complex could improve the efficiency of CTL testing. ${ }^{11-13}$

Due to its unique physical, chemical, and biological properties, graphene is at the frontier of nanotechnology. ${ }^{14-16}$ With its two-dimensional matrix structure, graphene is 
considered to be a single layer of stripped graphite ${ }^{17}$ and plays multiple roles in biomedical applications through introducing hydroxyl, carbonyl, and epoxy groups, ${ }^{18,19}$ as well as in antibodies, medicines, and functional nanoparticles. ${ }^{16,20,21}$ For example, graphene can be loaded with hemin through a $\pi-\pi$ conjugation effect, ${ }^{22,23}$ and the amino groups in streptavidin can be reacted with carboxyl groups on modified graphene. ${ }^{24,25}$ A biotinylated MHC monomer, thus, can be loaded onto a graphene surface through biotin-streptavidin effect. ${ }^{21,26}$

Here, based on graphene, a novel CTL detection probe and related detection model were evaluated. The hemin functionalized reduced graphene oxide (HRGO) was first constructed and subsequently loaded with an MHC-peptide complex through the biotin-streptavidin reaction to prepare graphene-based MHC-peptide multimers (HRGO/pMHC multimers). The capture probe was prepared by adding a biotinylated $\mathrm{MHC}$ monomer in streptavidin-preincubated plates to bind CTLs. The HRGO/pMHC multimers selectively bound to the T-cells, while the number of T-cells was detected through the catalytic reaction between HRGO and tetramethylbenzidine (TMB) $/ \mathrm{H}_{2} \mathrm{O}_{2}$. The detection efficiency of this probe was evaluated under different circumstances and compared with phycoerythroprotein (PE)/pMHC tetramers.

\section{Materials and methods Materials}

Graphene was purchased from Nanjing Xianfeng Nano Materials Tech Co. Ltd (Nanjing, China). Biotinylated HLA-A*0201restricted $\mathrm{AFP}_{158-166} \mathrm{MHC}$ monomer and MAGE-A $1_{278-286}$ $\mathrm{MHC}$ monomer were purchased from Beijing Kuangbo Co. Ltd (Beijing, China). Hemin, PE-conjugated streptavidin antibody, and streptavidin ELISA plates were purchased from Sigma Aldrich (St Louis, MO, USA). Antigen peptide SLYNTVATL (SL9), FMNKFIYE (AFP $\left.{ }_{158-166}\right)$, and KVLEYVIKV (MAGE-A1 ${ }_{278-286}$ ) were obtained from Hangzhou Zhongtai Co. Ltd (Hangzhou, China). The TAP-deficient HLA-A2 ${ }^{+}$cell line (T2 cell line) was obtained from the American Type Culture Collection. T2 cells were grown in RPMI 1640 (Thermo Fisher Scientific, Waltham, MA, USA) supplemented with $15 \%$ fetal bovine serum (Hyclone, Logan, UT, USA), $50 \mathrm{U} / \mathrm{mL}$ penicillin, and $50 \mu \mathrm{g} / \mathrm{mL}$ streptomycin in $5 \% \mathrm{CO}_{2}$ at $37^{\circ} \mathrm{C}$ in a humidified incubator. All chemicals used were of the highest purity available. The peripheral blood of hepatoma patients and healthy individuals was provided by the Clinical Laboratory of Chun'an First People's Hospital (Zhejiang, China). All patients and volunteers provided written informed consent. The studies involving blood samples were approved by the Medical Ethics Committee of Chun'an First People's Hospital.

\section{Synthesis of HRGO}

Graphene oxide (GO) solid powder (1 mg) was dissolved in ultra-pure water $\left(\mathrm{ddH}_{2} \mathrm{O} ; 1 \mathrm{~mL}\right)$. The suspension was sonicated to a uniform dispersion. To obtain the hemin functionalized graphene oxide (HGO), $5 \mathrm{mg} / \mathrm{mL}$ hemin was added into the suspension which was treated with vortex oscillation. After bathing at $60^{\circ} \mathrm{C}$ water for 4 hours, the uncombined hemin was washed away using sterile, ultra-pure water $\left(\mathrm{ddH}_{2} \mathrm{O}\right)$. To obtain the HRGO, hydrazine hydrate was added after hemin treatment.

\section{Synthesis of HRGO/MHC-peptide multimers and $\mathrm{PE} / \mathrm{PMHC}$ tetramers}

$\mathrm{HRGO}(1 \mathrm{mg} / \mathrm{mL}, 50 \mu \mathrm{L})$ and 1-ethyl-3(3-dimethyl aminopropyl) carbodiimide carbodiimide (EDC)/N-hydroxysuccinimide (NHS) $(0.1 \mathrm{M}, 10 \mu \mathrm{L})$ were mixed and then incubated at room temperature for 1 hour. Streptavidin $(1 \mu \mathrm{M}, 10 \mu \mathrm{L})$ was added into the solution and stirred. After incubation at $4^{\circ} \mathrm{C}$ overnight, the uncombined streptavidin was washed away using $\mathrm{ddH}_{2} \mathrm{O}$. To obtain $\mathrm{HRGO} / \mathrm{pMHC}$ multimers, 4 $\mu \mathrm{L}$ of the biotinylated $\mathrm{MHC}$-peptide monomer $(1 \mu \mathrm{M})$ was added into the streptavidin-HRGO ten times every 10 minutes in a dark environment. Similarly, $5 \mu \mathrm{L}$ of biotinylated $\mathrm{MHC}-$ peptide monomer $(1 \mu \mathrm{M})$ was added to the PE-conjugated streptavidin antibody solution $(1 \mu \mathrm{M})$ and stirred in the dark ten times every 10 minutes. The compounds were then purified using a $100 \mathrm{kDa}$ membrane filter to obtain PE/pMHC tetramers. The synthetic reagents were all stored at $4^{\circ} \mathrm{C}$.

\section{Characterizations}

The optical absorbance characteristic of hemin, HGO, and HRGO, was investigated by ultraviolet (UV)-visible absorption spectra (F-7000, Thermo Fisher Scientific). Fourier transform infrared radiation spectra (TL-8000; Bruker Optik GmbH, Ettlingen, Germany) were used to identify the functional groups on the nanomaterials. The distribution of probe diameters was determined using a laser particle size analyzer (Zeta sizer Nano ZS; Malvern Instruments, Malvern, UK). The zeta potential of samples was measured by zeta potential analyzer (Zeta sizer Nano ZS; Malvern), and all the samples were dispersed in water of $\mathrm{pH}=$ 7.0. Thermogravimetric analysis (TGA 4000; PerkinElmer) was performed with a thermogravimetric speed of $4^{\circ} \mathrm{C} / \mathrm{min}$ and automatic cooling to $50^{\circ} \mathrm{C}$ after heating to $800^{\circ} \mathrm{C}$.

\section{Induction of hepatocellular carcinoma- specific T-cells in vitro}

T2 cells were incubated with the antigen peptide $\mathrm{AFP}_{158-166}$ $(40 \mu \mathrm{g} / \mathrm{mL})$ for 6 hours. After 200 Gy X-ray irradiation, 
cells were centrifuged at 1,500 rpm for 5 minutes. Cells were collected and resuspended in serum-free RPMI 1640. Peripheral blood mononuclear cells from clinical blood samples were isolated using the Ficoll-Hypaque gradient method. Peripheral blood mononuclear cells were cultured in tissue culture bottles for 2 hours to obtain adherent $\mathrm{T}$ lymphocytes. Subsequently, antigen peptide $\mathrm{AFP}_{158-166^{-}}$ loaded T2 cells (T2/AFP $\left.{ }_{158-166}\right)$ were co-incubated with peripheral $\mathrm{T}$ lymphocytes in complete medium. IL-2 $(20 \mathrm{U} / \mathrm{mL})$ and IL-7 $(5 \mathrm{ng} / \mathrm{mL})$ were added at day 1 and day 4 , respectively. These cytokines were supplemented every 3 days. The medium was replaced twice a week and T2/AFP ${ }_{158-166}$ was added once a week for 3 weeks.

\section{Identification of hepatocellular carcinoma-specific T-cells by HRGO/ PMHC multimers}

Biotinylated antigen peptide-MHC monomer $(1 \mu \mathrm{M}, 10 \mu \mathrm{L})$ was incubated in streptavidin 96-well plates in a dark environment for 20 minutes. After repeating ten times, the plates were washed with $0.5 \% \mathrm{BSA}$. The induced $\mathrm{AFP}_{158-166}$-specific T-cells $\left(1 \times 10^{6}\right.$ cells $)$ were added into pMHC monomermodified plates in a dark environment at $4^{\circ} \mathrm{C}$ for 1 hour. $\mathrm{HRGO/pMHC}$ multimers were added and stirred for 1 hour. To remove the uncombined substances, ultrapure water was used to wash the plate well several times. To reflect the frequency of CTLs, $100 \mu \mathrm{L}$ TMB substrate and $1 \mu \mathrm{L} \mathrm{H}_{2} \mathrm{O}_{2}$ $(500 \mathrm{mM})$ were added. Then the plates were set on a platform rocker at $37^{\circ} \mathrm{C}$ for 30 minutes (for optimized data of TMB, $\mathrm{H}_{2} \mathrm{O}_{2}$, and colorimetric reaction time, see Figure $\mathrm{S} 1$ ). The absorption spectra of the samples at a wavelength of $650 \mathrm{~nm}$ were measured by Multiskan Spectrum (Thermo Fisher Scientific).

\section{Identification of hepatocellular carcinoma-specific T-cells by PE/pMHC tetramers}

The T-cells were collected by centrifugation and washed three times with PBS. After incubation with both PE/pMHC tetramers and fluorescein isothiocyanate-CD8 in the dark, cells were washed again, collected, and analyzed with flow cytometry (Beckman Coulter, Inc., Brea, CA, USA). The flow cytometry data were analyzed in real time using Expo32 ADC 1.1C (Beckman Coulter, Inc.).

\section{Statistical analysis}

All data are given as mean \pm SD. For statistical evaluation, the independent $t$-test was used for comparison between groups. GraphPad Prism software version 6.0 (La Jolla, CA, USA) was used for data analysis. $P$-values $<0.05$ were considered as statistically significant. Least significant difference, Student-Newman-Keuls, and Bonferroni post hoc tests were used.

\section{Results}

The preparation procedure and working principle of HRGO/pMHC multimers for CTL detection

Since graphene can be easily modified with functional groups, or loaded with antibodies, medicines, and other nanoparticles, it has been widely used in the field of biomaterials. As shown in Figure 1, based on graphene, we created a novel probe for CTL detection. The detection probes were $\mathrm{HRGO/pMHC}$ multimers consisting of graphene, hemin, streptavidin, and biotinylated MHC monomers. The capture probes were 96-well plates modified with pMHC multimers consisting of streptavidin and biotinylated MHC monomers. Both probes and CTLs made a sandwich structure: HRGO/ pMHC multimers-CTLs-plates. The frequency of CTLs was proportional to the number of hemin molecules in the sandwich structure.

\section{Characterization of graphene and composite nanomaterials}

The load of hemin on GO was investigated using UV-vis spectrometry. As shown in Figure 2A, the absorbance peaks of GO and hemin were 230 and $388 \mathrm{~nm}$, respectively. The hemin-conjugated GO (HGO) had nearly the same absorbance characteristics as pristine GO, while the hemin absorbance peak in UV-vis spectra shifted from 388 to $403 \mathrm{~nm}$. While hemin was loaded on reduced graphene oxide (RGO), the peaks of GO and hemin were red-shifted to 272 and $419 \mathrm{~nm}$, respectively. Hemin content on HRGO was higher than that on HGO, which was determined from the relative hemin absorbance peak intensity. TGA results depicted in Figure 2B show two falling inflection points were found in the TGA curve of GO, while one point was observed for hemin. The inflection point of the HRGO fell in between. By a combination of the results above, both HRGO and HRGO/ pMHC multimers were successfully prepared. In addition, Fourier transform infrared radiation was used to measure the functional groups on GO, hemin, HRGO, and streptavidin functionalized $\mathrm{HRGO}$ (Figure 2C). GO showed the functional groups of $\mathrm{C}-\mathrm{O}\left(\sim 1,264 \mathrm{~cm}^{-1}\right)$ and $\mathrm{C}-\mathrm{O}-\mathrm{C}\left(\sim 1,103 \mathrm{~cm}^{-1}\right)$. In addition to these peaks, HRGO also showed that a strong 

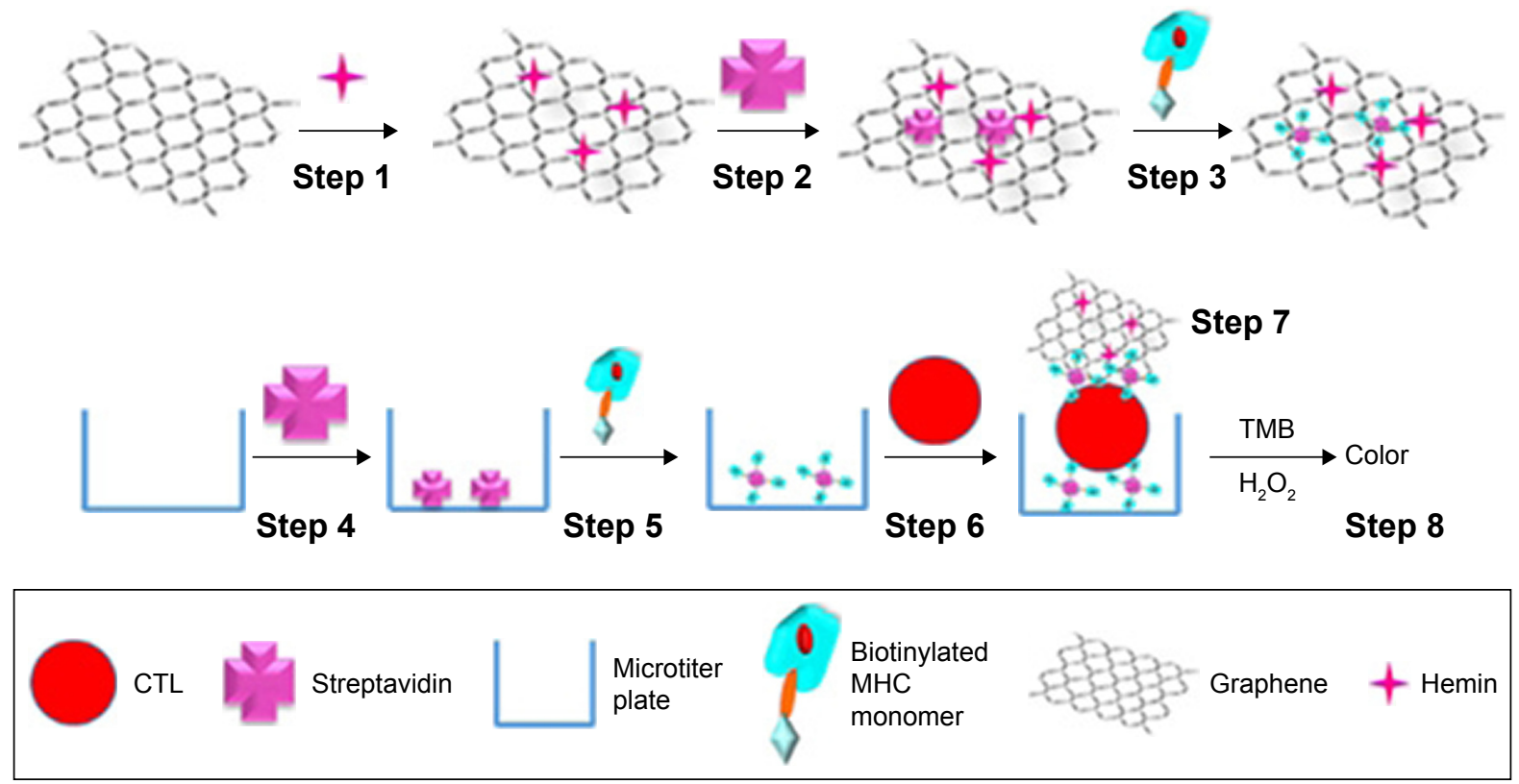

Figure I Schematic diagram of the synthesis of HRGO/pMHC multimers as CTL detection probes and the detection process of the new graphene-based assay. Notes: First, hemin was bound onto GO to create the HRGO through ח- - covalent linkage (Step I). Streptavidin was subsequently bound onto HRGO through the reaction between amino groups from streptavidin and the carboxyl groups on HRGO (Step 2). Next, the biotinylated pMHC monomer was loaded onto streptavidin-HRGO via biotin-streptavidin affinity to create the CTL detection probe (Step 3), graphene based (HRGO/pMHC multimers). The biotinylated pMHC monomer was also added into streptavidin-preincubated plates through biotin-streptavidin (Step 4) to create the capture probe (Step 5), which can selectively catch CTLs (Step 6). Finally, the HRGO/ PMHC multimers selectively bound to CTLs (Step 7) were induced to detect the frequency of CTLs through the catalytic reaction between $\mathrm{HRGO}$ and TMB/ $\mathrm{H}_{2} \mathrm{O}_{2}\left(\mathrm{Step}_{8}\right.$ ). The absorption spectrum of the solvent around $650 \mathrm{~nm}$ was measured to determine the amount of hemin on HRGO. Sensitive detection, thus, can be achieved by the positive correlation between hemin and CTL amount.

Abbreviations: CTL, cytotoxic T lymphocyte; GO, graphene oxide; HRGO, hemin reduced graphene oxide; MHC, major histocompatibility complex; PMHC, major histocompatibility complex peptide; TMB, tetramethylbenzidine.

characteristic peak existed on hemin $\left(\sim 1,050 \mathrm{~cm}^{-1}\right)$. When HRGO was modified with streptavidin, the absorbance peak which represented $-\mathrm{CONH}-\left(1,622 \mathrm{~cm}^{-1}\right)$ shifted to $\left(1,590 \mathrm{~cm}^{-1}\right)$ and the transmittance increased, suggesting a successful connection of RGO, hemin, and streptavidin.

As shown in Figure 3A and B, after introduction of hemin onto RGO and the subsequent loading of biotinylated pMHC monomers onto HRGO, the average particle size increased from $279.1 \pm 3.4$ to $288.6 \pm 5.1$ and $290.5 \pm 7.2 \mathrm{~nm}$, respectively. In addition, the zeta potential changed from $-30.5 \pm 1.3$ to $-25.0 \pm 0.8$ and $-23.0 \pm 1.5 \mathrm{mV}$, respectively. The increase in particle size can be attributed to the covering of GO with hemin and biotinylated pMHC monomers, which also caused the decrease in negative zeta potential because of the reduction in oxygen-containing functional groups on the surfaces of GO.

\section{The efficiency of HRGO catalyzing TMB reaction}

As mentioned above, the frequency of T-cells is determined by the catalytic reaction between the hemin on graphene and TMB. Therefore, it is necessary to evaluate the sensitivity of
HGO and HRGO to catalyze the TMB reaction. As shown in Figure 4A, the sensibility of HRGO was higher than HGO, since a higher absorbance peak around $650 \mathrm{~nm}$ was obtained (Figure 4B). The reason can be attributed to the higher hemin content on HRGO than that on HGO. More importantly, TMB response signals were detected at different HRGO concentrations (Figure 4C). When HRGO was diluted to as low as $0.3 \mu \mathrm{g} / \mathrm{mL}$ (Figure 4D), the signal was still detectable, demonstrating that HRGO can catalyze the TMB reaction sensitively, and thus can potentially be used as the detection probe.

\section{Identification of stable HLA-A2 expression on $\mathrm{T} 2$ cells pulsed with antigen peptide and on hepatocellular carcinoma- specific $T$ lymphocyte cells in vitro}

To ensure the expression of HLA-A2 on T2 cells, expression of HLA-A2 on the surface of T2/AFP ${ }_{158-166}$ cells was tested by flow cytometry. Antigen peptide $\mathrm{AFP}_{158-166}$ at a concentration of 20 and $40 \mu \mathrm{g} / \mathrm{mL}$ was incubated with $\mathrm{T} 2$ cells. Results showed that $7.8 \%$ T2 cells expressed HLA-A2 molecules without being pulsed with $\mathrm{AFP}_{158-166}$. Also, 70.6\% 

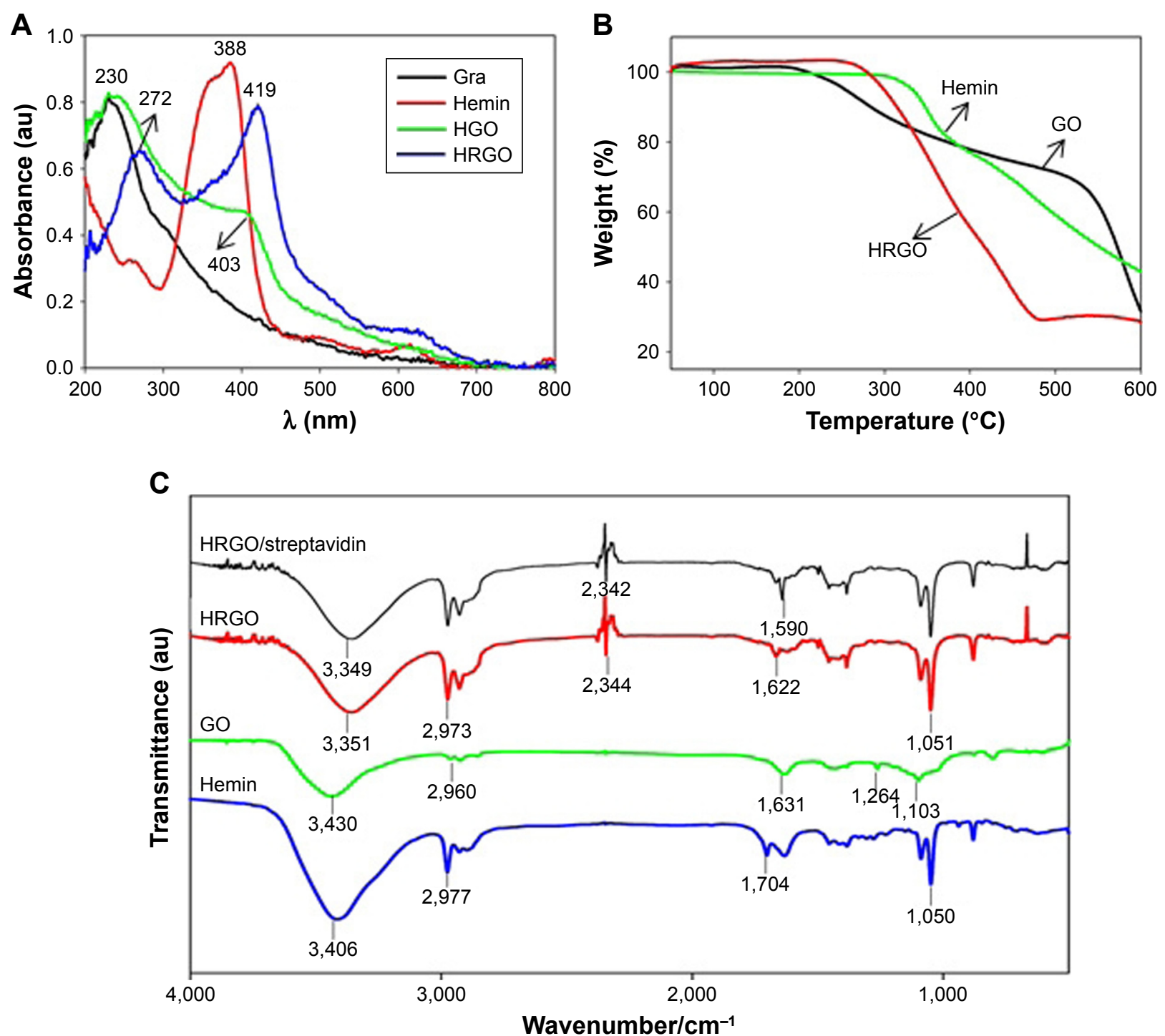

Figure 2 Absorbence peaks of GO and hemin.

Note: (A) Absorption spectra, (B) thermogravimetric analysis, and (C) infrared spectroscopy of nanoparticles. (A) The origin and end of the arrow in represent the absorbance peak position and the value of the absorbance peak respectively. (B) The arrow indicates the corresponding nanomaterial for each absorption spectrum. Abbreviations: GO, graphene oxide; HGO, hemin functionalized graphene oxide; HRGO, hemin functionalized reduced graphene oxide.

T2 cells expressed HLA-A2 when pulsed with $20 \mu \mathrm{g} / \mathrm{mL}$ antigen peptide. When $\mathrm{T} 2$ cells were loaded with $40 \mu \mathrm{g} / \mathrm{mL}$ antigen peptide $\mathrm{AFP}_{158-166}$, the frequencies increased to $96.3 \%$ (Figure 5A), demonstrating that HLA-A2 molecules were expressed stably on $\mathrm{T} 2$ cells.

To test the expansion of CTLs in vitro, during cell induction, the frequencies of $\mathrm{AFP}_{158-166}$-specific T-cells were evaluated with conventional $\mathrm{PE} / \mathrm{pMHC}$ tetramers every week. The results of the flow cytometric assay showed that after in vitro induction for 21 days, the frequencies of antigen peptide $\mathrm{AFP}_{158-166}$-specific T-cells increased (Figure 5B), in comparison with the negative control of HIV-gag ${ }_{77-85}$ (SL9) tetramers. These results indicated that $\mathrm{AFP}_{158-166}$-specific T-cells were successfully induced in vitro.

\section{Comparison of the detection limit of hepatocellular carcinoma-specific T-cells with $\mathrm{HRGO} / \mathrm{pMHC}$ multimers and $\mathrm{PE} / \mathrm{PMHC}$ tetramers}

In order to compare the detection efficiency of HRGO/ pMHC multimers and PE/pMHC tetramers, T-cells with a detection frequency of $2.2 \%$ by flow cytometry were divided into two groups and diluted to different concentrations. One group was tested with HRGO/MHC-peptide multimers using absorption spectrometry, and the other group was detected by the flow cytometry assay. As shown in Figure 6A, when the number of $\mathrm{AFP}_{158-166}$-specific T-cells was diluted to $2 \times 10^{3}$ per sample, the detection signal (absorbance peak) 
A
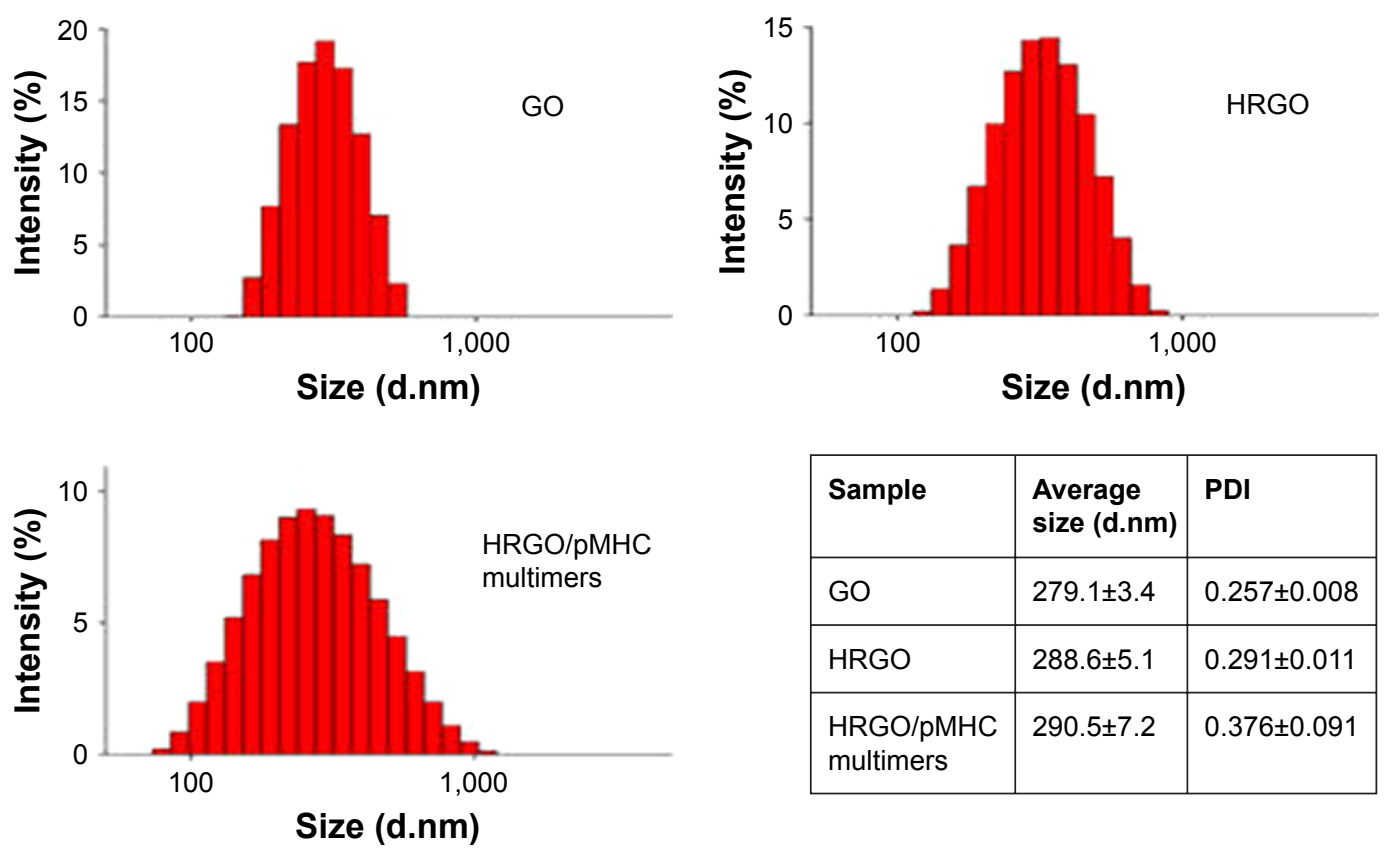

\begin{tabular}{|l|l|l|}
\hline Sample & $\begin{array}{l}\text { Average } \\
\text { size (d.nm) }\end{array}$ & PDI \\
\hline GO & $279.1 \pm 3.4$ & $0.257 \pm 0.008$ \\
\hline HRGO & $288.6 \pm 5.1$ & $0.291 \pm 0.011$ \\
\hline $\begin{array}{l}\text { HRGO/pMHC } \\
\text { multimers }\end{array}$ & $290.5 \pm 7.2$ & $0.376 \pm 0.091$ \\
\hline
\end{tabular}

B
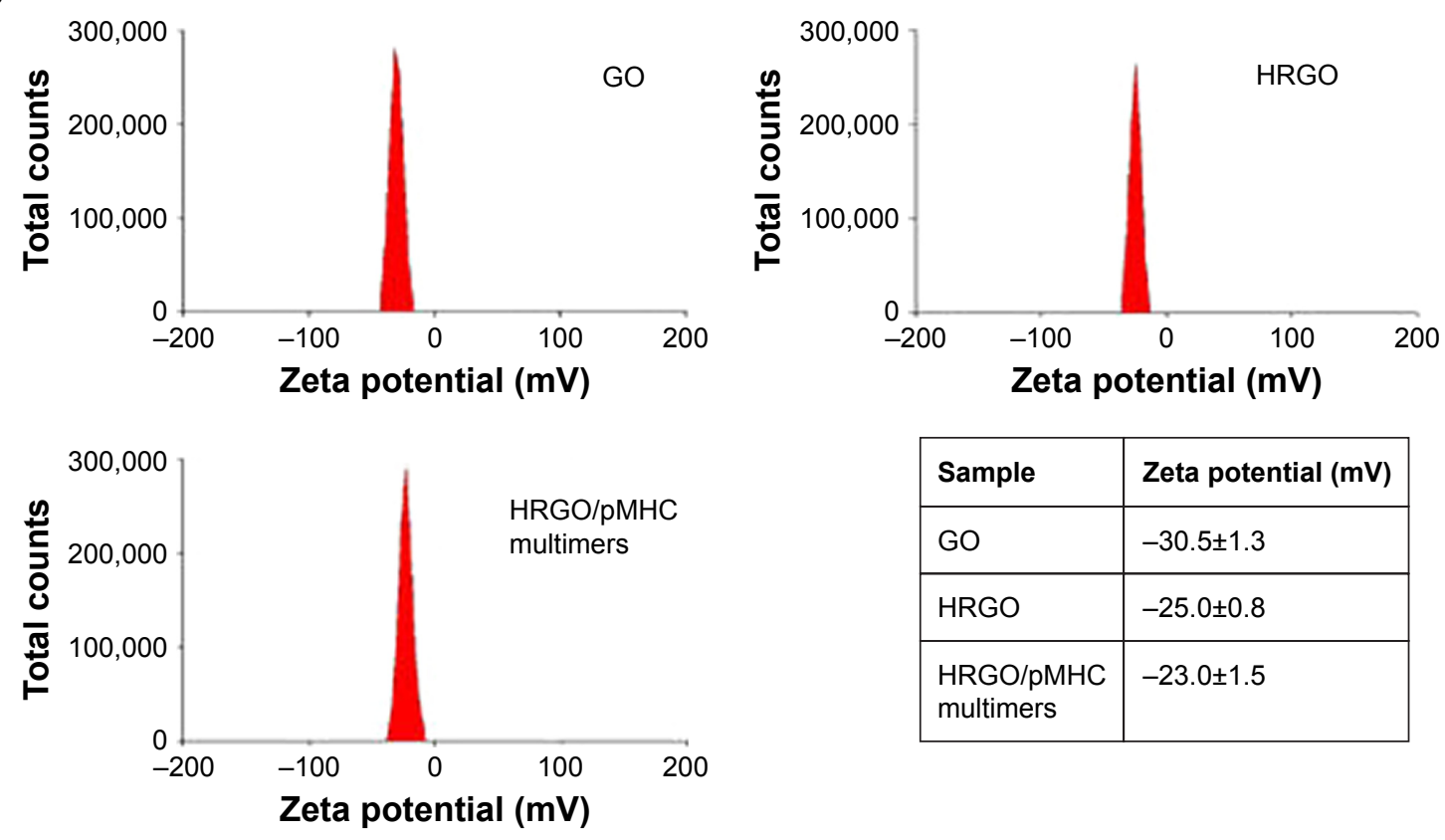

\begin{tabular}{|l|l|}
\hline Sample & Zeta potential $(\mathbf{m V})$ \\
\hline GO & $-30.5 \pm 1.3$ \\
\hline HRGO & $-25.0 \pm 0.8$ \\
\hline $\begin{array}{l}\text { HRGO/pMHC } \\
\text { multimers }\end{array}$ & $-23.0 \pm 1.5$ \\
\hline
\end{tabular}

Figure 3 Average particle size after introduction of hemin onto RGO and the subsequent loading of biotinylated pMHC monomers onto HRGO. Notes: (A) Particle size and (B) zeta potential of GO, HRGO, and HRGO/pMHC multimers.

Abbreviations: GO, graphene oxide; HRGO, hemin reduced GO; PDI, polydispersity index; pMHC, major histocompatibility complex peptide.

of $\mathrm{AFP}_{158-166}$-specific T-cells labeled with $\mathrm{HRGO} / \mathrm{pMHC}$ multimers was still evident. The linear calibration curve (Figure 6B) against T-cells concentration showed 0.14 when the number of T-cells was $2 \times 10^{3}$ and 0.04 in the absence of T-cells. The signal-to-background ratio was high (3.5). When the number of T-cells increased, the measured values increased approximately linearly. However, when the cell number was decreased to $5 \times 10^{3}$, it was hard to detect the PE/ pMHC tetramer-labeled specific T-cells by flow cytometry (Figure 6C). These results indicated that the HRGO/pMHC multimer could be used to detect the target cells when the samples contained very few T-cells, its limit of detection was lower and detection range larger, but flow cytometry needed more T-cells. 
A

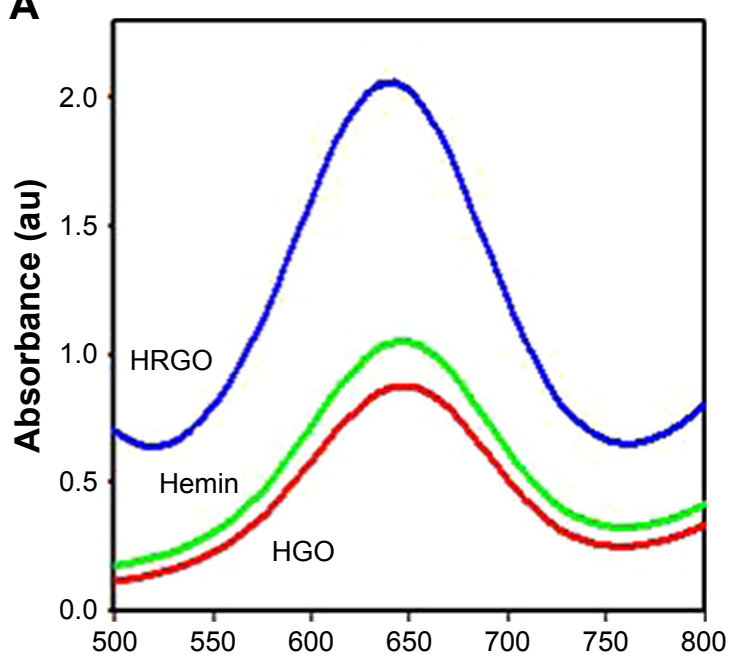

C

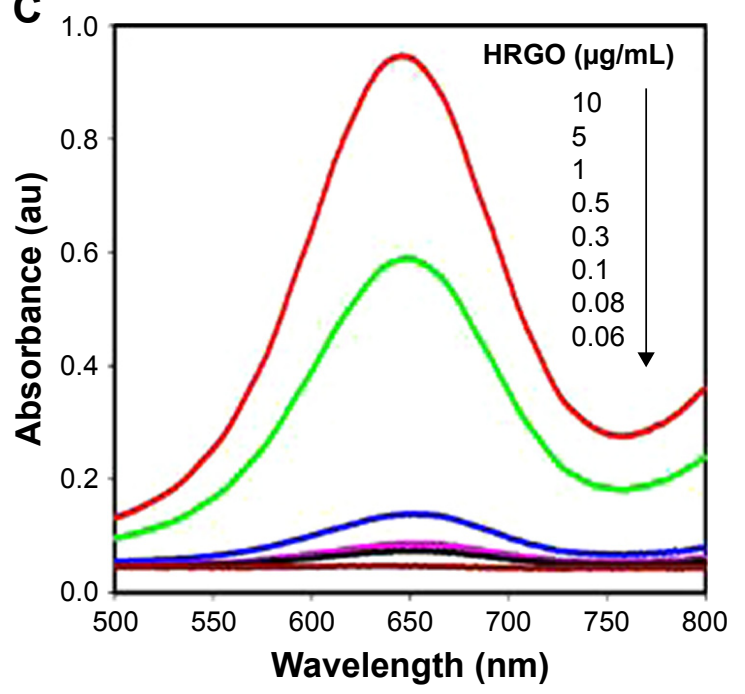

B

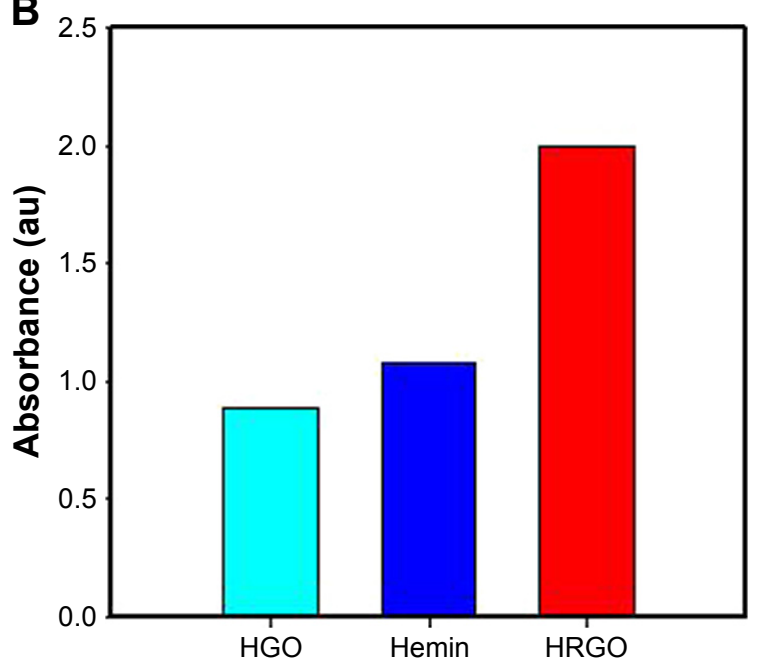

D

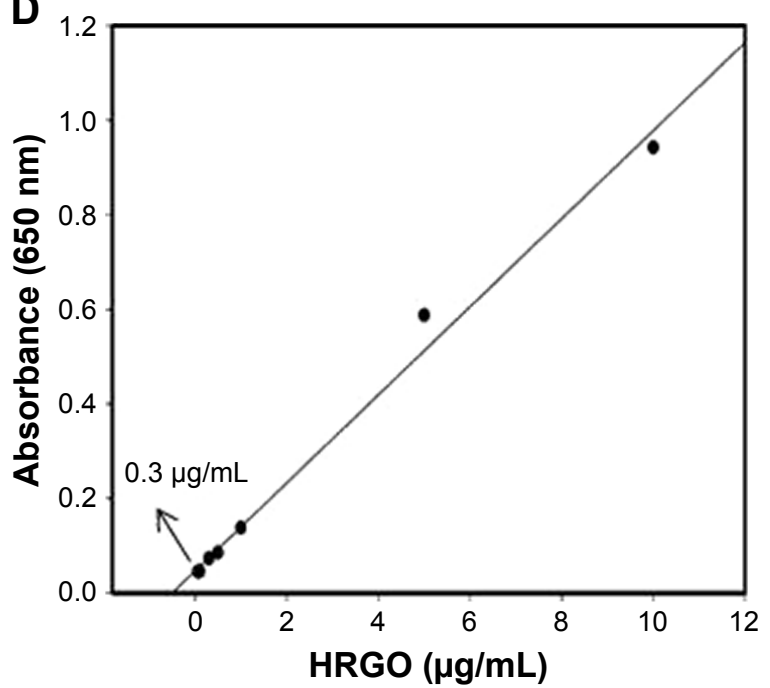

Figure 4 TMB response signals in response to different HRGO concentrations.

Notes: (A) Absorption spectra of the TMB reaction catalyzed by HGO, hemin, and HGRO. (B) The catalytic activity of the three materials was compared by a histogram. (C) Absorption spectra of the TMB reaction catalyzed by different concentrations of HRGO. (D) HRGO still shows a significant reaction signal at $0.3 \mu \mathrm{g} / \mathrm{mL}$. The signal to noise ratio is larger than 3 .

Abbreviations: HGO, hemin functionalized graphene oxide; HRGO, hemin reduced GO; TMB, tetramethylbenzidine.

\section{Comparison of the frequencies of} hepatocellular carcinoma-specific T-cells detected by $\mathrm{HRGO} / \mathrm{pMHC}$ multimers and $\mathrm{PE} / \mathrm{PMHC}$ tetramers

To further evaluate the ability of $\mathrm{HRGO} / \mathrm{pMHC}$ multimers to detect specific T-cells, the frequencies of $\mathrm{AFP}_{158-166}$ or MAGE-A $1_{278-286}$-specific T-cells in ten clinical peripheral blood samples from eight hepatocellular carcinoma patients and two healthy persons were evaluated. The frequencies of $\mathrm{AFP}_{158-166}$ and MAGE-A1 ${ }_{278-286}$-specific T-cells were first detected by $\mathrm{PE} / \mathrm{pMHC}$ tetramers. For the hepatocellular carcinoma-specific T-cells from the eight hepatocellular carcinoma patients, by flow cytometry (Figure 7A and B), the cells labeled by $\mathrm{PE} / \mathrm{AFP}_{158-166}$ tetramers or PE/MAGE$\mathrm{A}_{278-286}$ tetramers were little higher in comparison with the negative control based on PE/SL9 tetramers. On the other hand, the absorption peaks representing the number of hepatocellular carcinoma-specific T-cells determined by HRGO/SL9 multimers were lower than the absorption peaks (shown as solid curves) determined by $\mathrm{HRGO} / \mathrm{AFP}_{158-166}$ multimers or HRGO/MAGE-A1 ${ }_{278-286}$ multimers (Figure 7C and $\mathrm{D})$. For the other two samples from two healthy persons, we found the detection results of the new assay display as well as the flow cytometry method to be very similar between positive groups and negative groups. As the number of hepatocellular carcinoma-specific T-cells in healthy people 

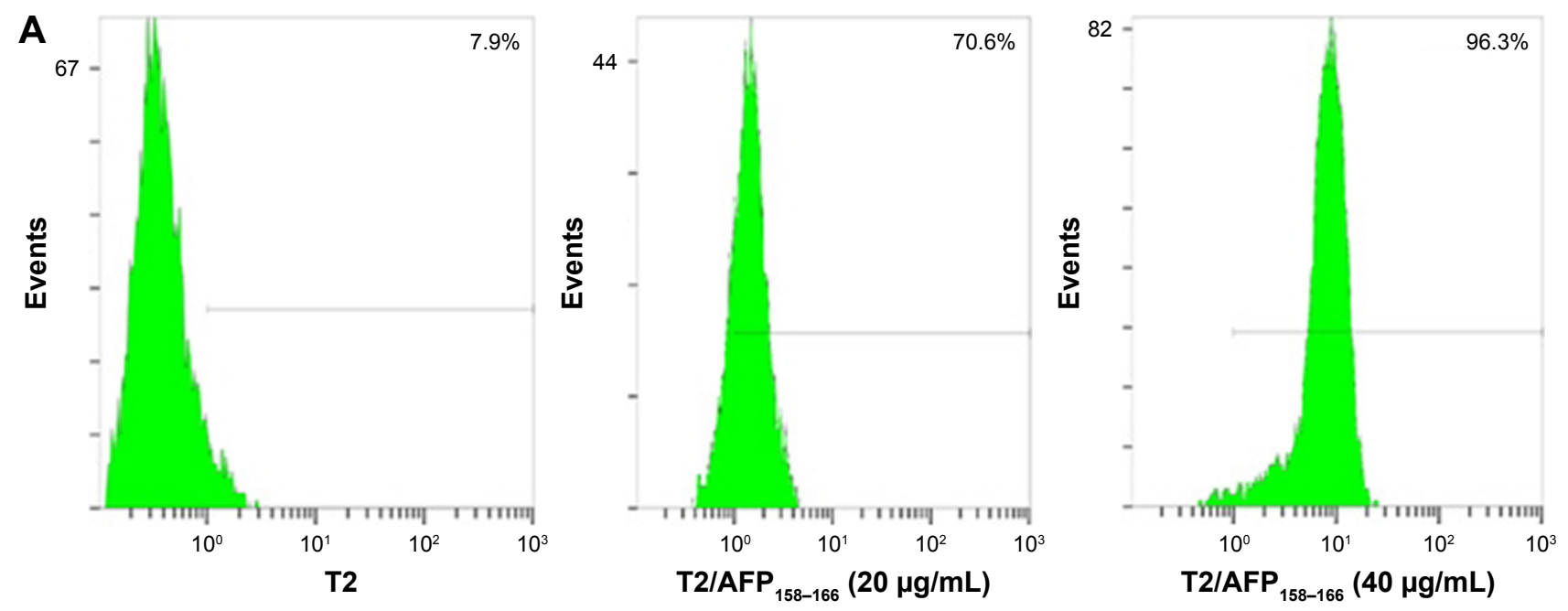

B

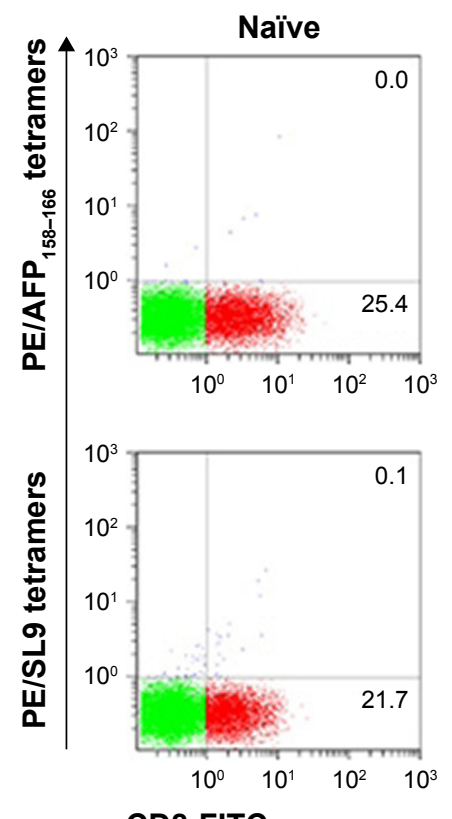

Day 7
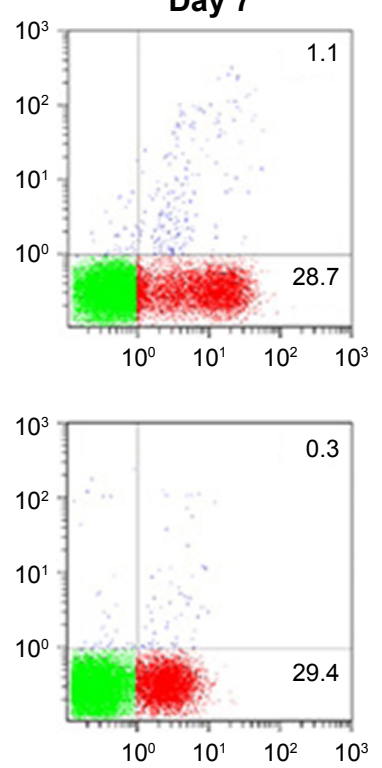

Day 14
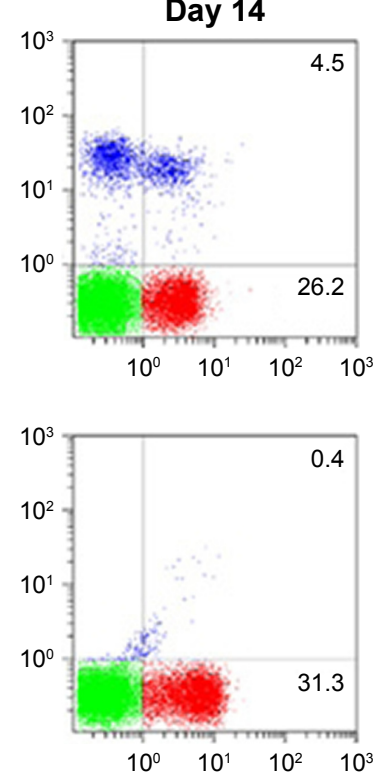

Day 21
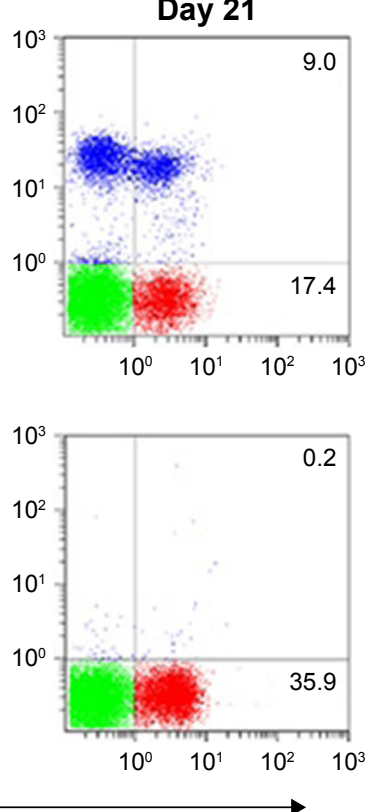

Figure 5 Expression of HLA-A2 molecules on T2 cells.

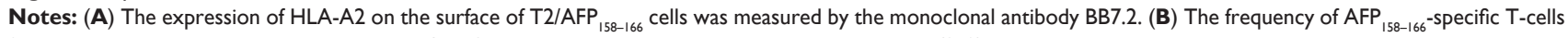

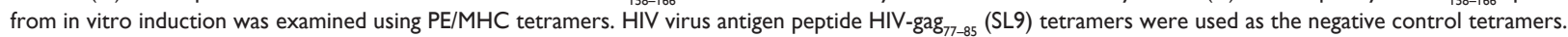

Abbreviations: FITC, fluorescein isothiocyanate; MHC, major histocompatibility complex; PE, phycoerythroprotein.

is extremely small, this result supports the conclusion that the new assay has good specificity.

\section{Statistical comparison of hepatocellular} carcinoma-specific T-cells detected by HRGO/pMHC multimers and PE/pMHC

\section{tetramers}

As the statistical data show in Figure 8, the frequencies of specific T-cells in peripheral blood of hepatocellular carcinoma patients identified by HRGO/MAGE-A $1_{278-286}$ multimers or $\mathrm{HRGO} / \mathrm{AFP}_{158-166}$ multimers were higher than the frequency detected by HRGO/SL9 multimers $(P<0.05)$.
On the other hand, $\mathrm{HRGO} / \mathrm{pMHC}$ multimers showed no difference in the detection of T-cells from two healthy individuals. Every clinical blood sample was tested and analyzed four times. The results of classic flow cytometry analysis and the new absorption spectra assay showed a similar trend: $\mathrm{HRGO} /$ pMHC multimers identified hepatocellular carcinomaspecific T-cells with high sensitivity and specificity.

\section{Discussion}

The aim of this study was to test a new method for the detection of hepatocellular carcinoma-specific T-cells. HRGO/ pMHC multimers were constructed as a detection probe for 

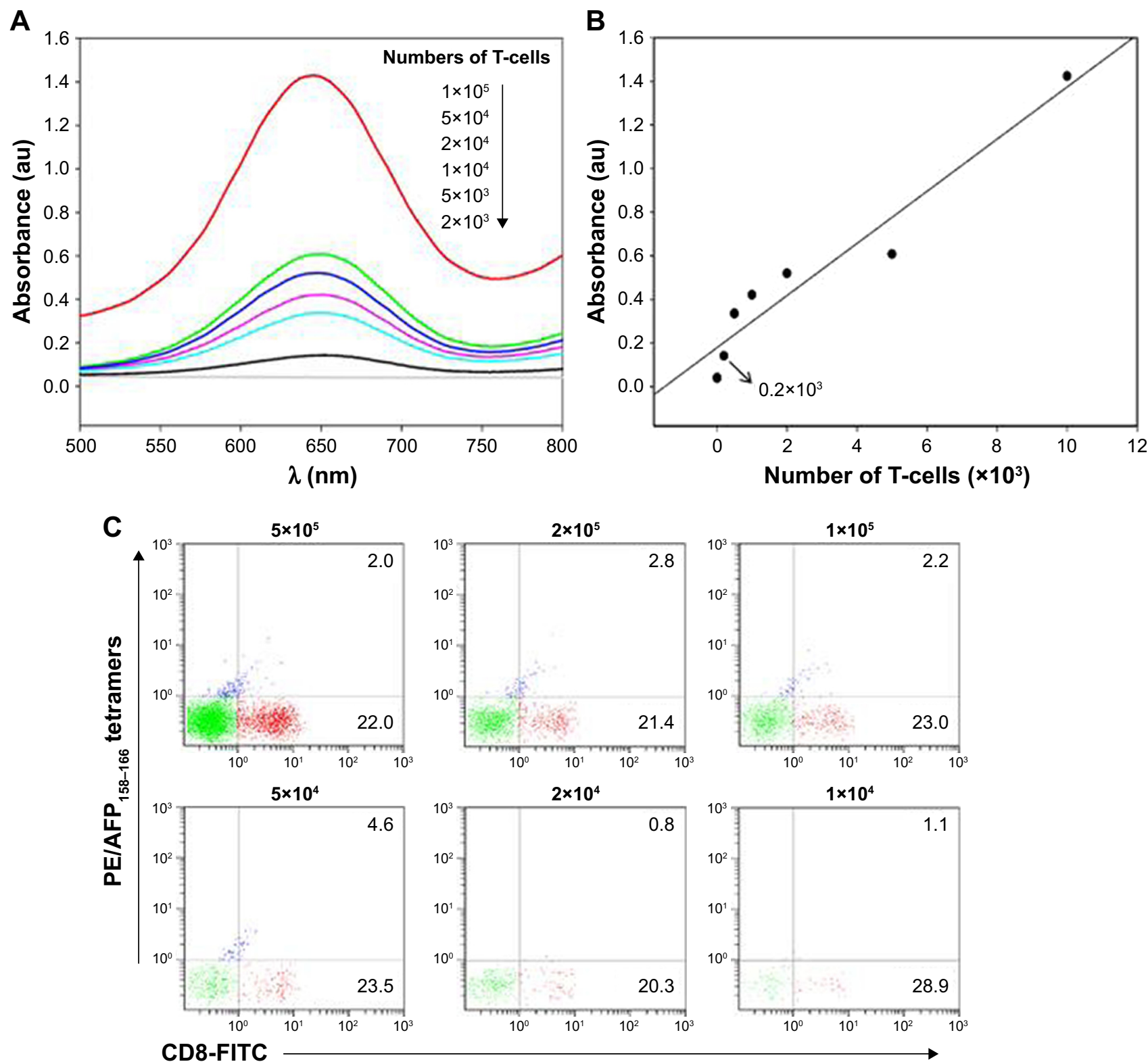

Figure 6 Absorbance peak of $\mathrm{AFP}_{158-166}$-specific T-cells labeled with HRGO/pMHC multimers.

Notes: (A) Detection limit of $\mathrm{AFP}_{158-166}$-specific T-cells indicated by UV absorbance spectrum with the HRGO/MHC multimers. (B) The linear calibration curve of the absorbance at $650 \mathrm{~nm}$ against T-cells concentration. (C) Detection limit of AFP ${ }_{158-166}$-specific T-cells indicated by flow cytometry assay. AFP $158-166$-specific $\mathrm{T}_{\text {-cells were diluted }}$ to different concentrations and measured with different detection probes.

Abbreviations: FITC, fluorescein isothiocyanate; HRGO, hemin reduced graphene oxide; MHC, major histocompatibility complex; pMHC, major histocompatibility complex peptide; UV, ultraviolet.

labeling CTLs, that is, the HRGO was first constructed and subsequently loaded with an MHC-peptide complex through biotin-streptavidin to prepare $\mathrm{HRGO} / \mathrm{pMHC}$ multimers. A biotinylated antigen $\mathrm{pMHC}$ monomer was modified on the surface of streptavidin-preincubated plates, while the $\mathrm{HRGO} /$ pMHC multimer was used as a detection probe to bind to the captured T-cells to form an "HRGO/pMHC multimer, antigenspecific T-cell, multimer-labeled plate" sandwich structure. In the presence of hydrogen peroxide, the catalysis of the peroxidase substrate color reaction was achieved. Based on the absorbance peak at $650 \mathrm{~nm}$, the hemin involved in the reaction was evaluated. Since the number of CTLs and hemin content was positively correlated, the specificity of CTL-sensitive detection could be achieved. The results demonstrated that the levels of specific CTLs could be detected selectively and sensitively with HRGO/pMHC multimers in both an induction system in vitro and the peripheral blood of patients. The CTL detection efficiency of the HRGO/pMHC multimers was significantly higher than that of $\mathrm{PE} / \mathrm{pMHC}$ tetramers.

This method has unique advantages over conventional flow detection methods. First, fluorescent-labeled antibodies are not required, eliminating the tedious step of dyeing. 
A
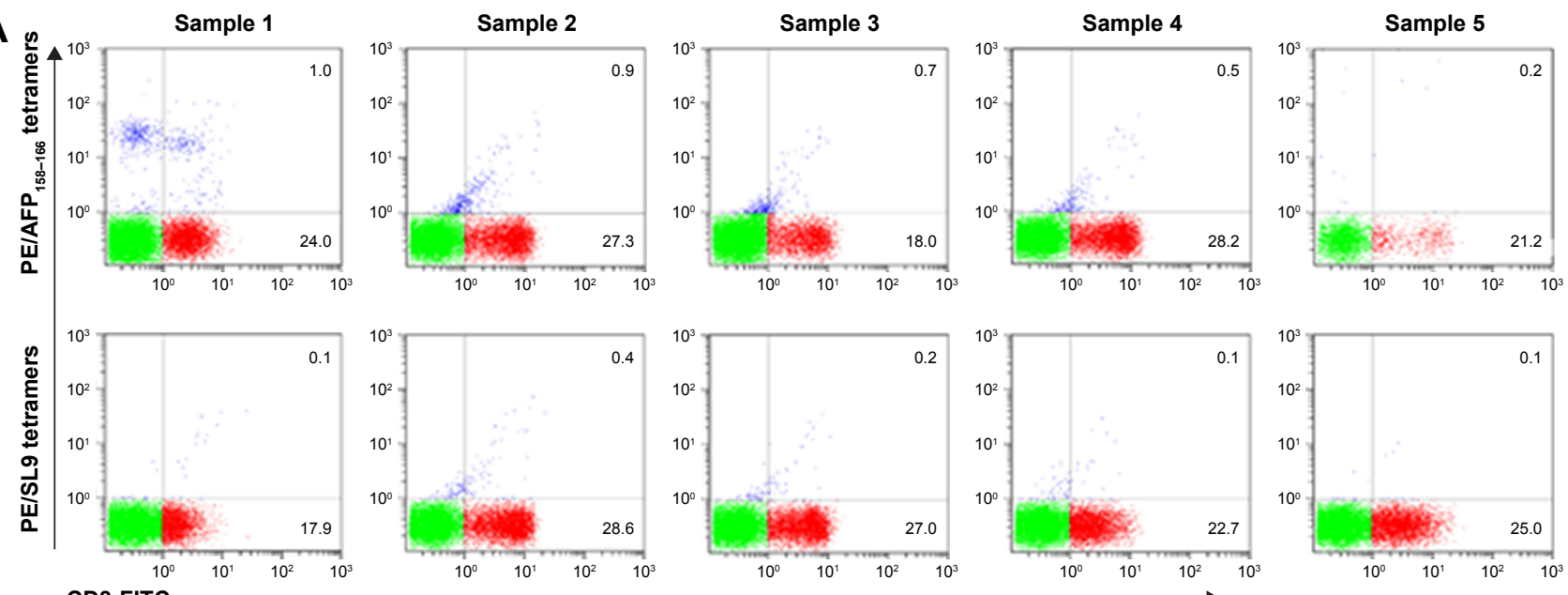

CD8-FITC

B
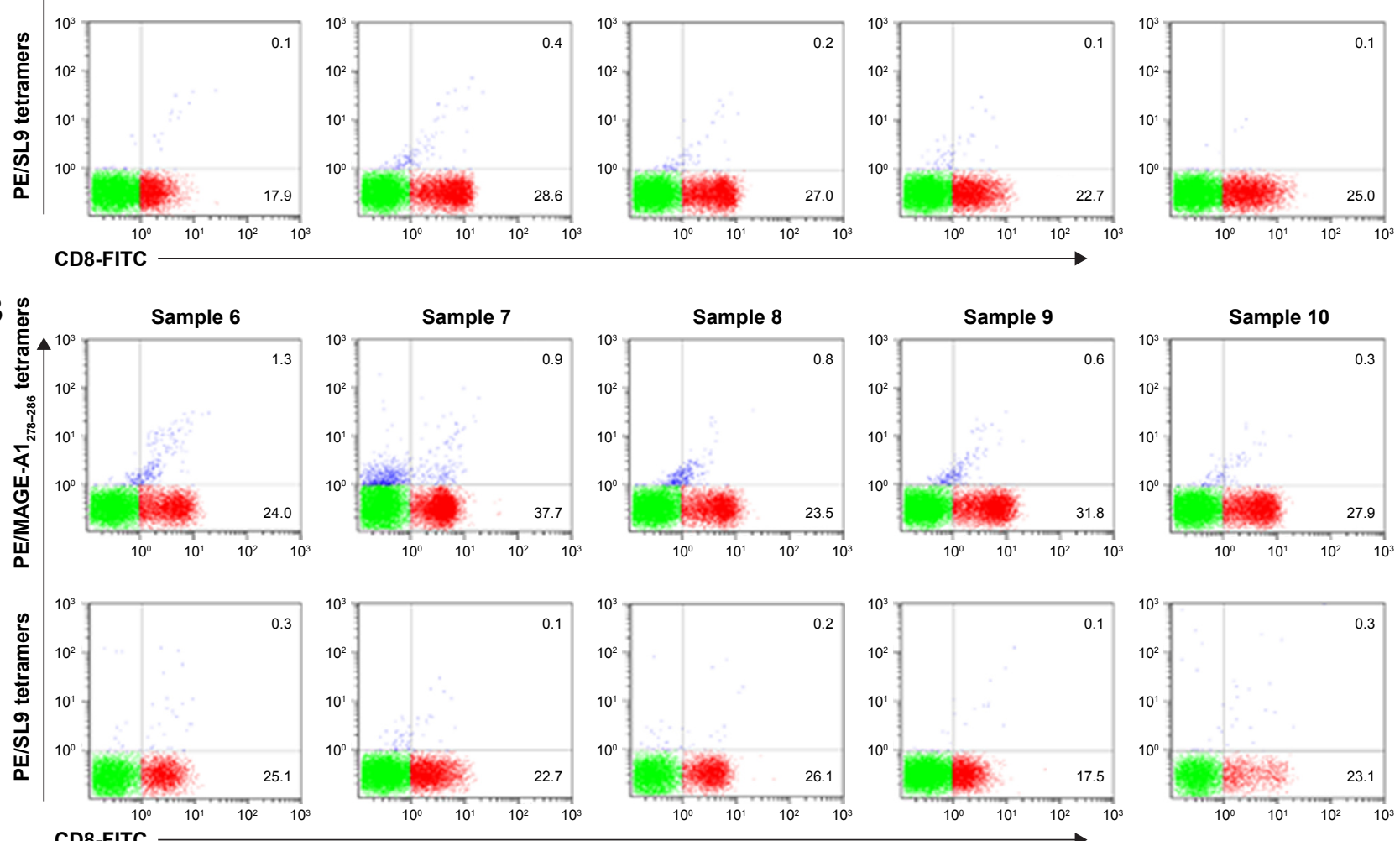

CD8-FITC
C

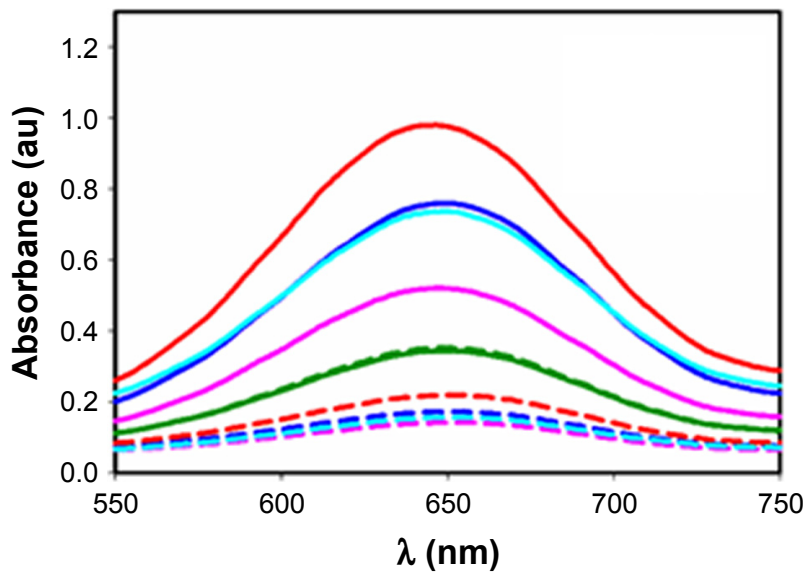

\begin{tabular}{|rr|}
\hline Sample 1 & Sample 2 \\
Sample 4 & Sample 5
\end{tabular}
D

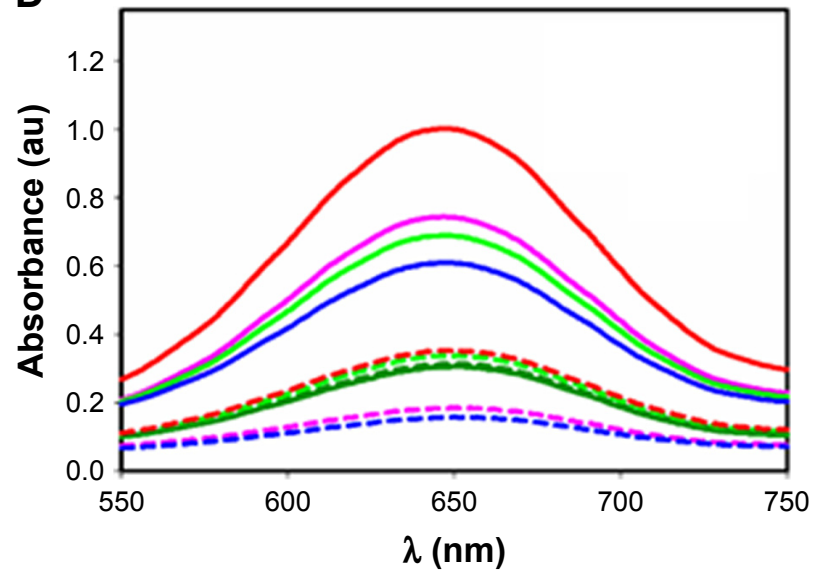

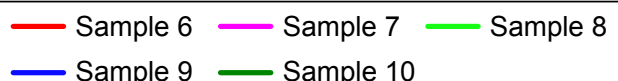

Figure 7 Specific T-cell detection with HRGO/pMHC multimers.

Notes: The frequency of AFP ${ }_{158-166}$-specific T-cells from ten blood samples (samples from four hepatocellular carcinoma patients and one healthy person) was detected by (A) flow cytometry and (B) the novel graphene-based assay. Similarly, the frequency of MAGE-AI ${ }_{278-286^{-}}$specific T-cells from separate samples (four hepatocellular carcinoma patients and one healthy person) was identified by (C) flow cytometry and the (D) novel graphene-based assay. Tetramers or multimers based on antigen peptide SL9 were used as the negative control. The result of every blood sample is shown as one solid curve and a dashed curve with the same color. Dashed curves represent the control groups and solid curves represent the experimental groups.

Abbreviations: FITC, fluorescein isothiocyanate; HRGO, hemin reduced graphene oxide; pMHC, major histocompatibility complex peptide. 

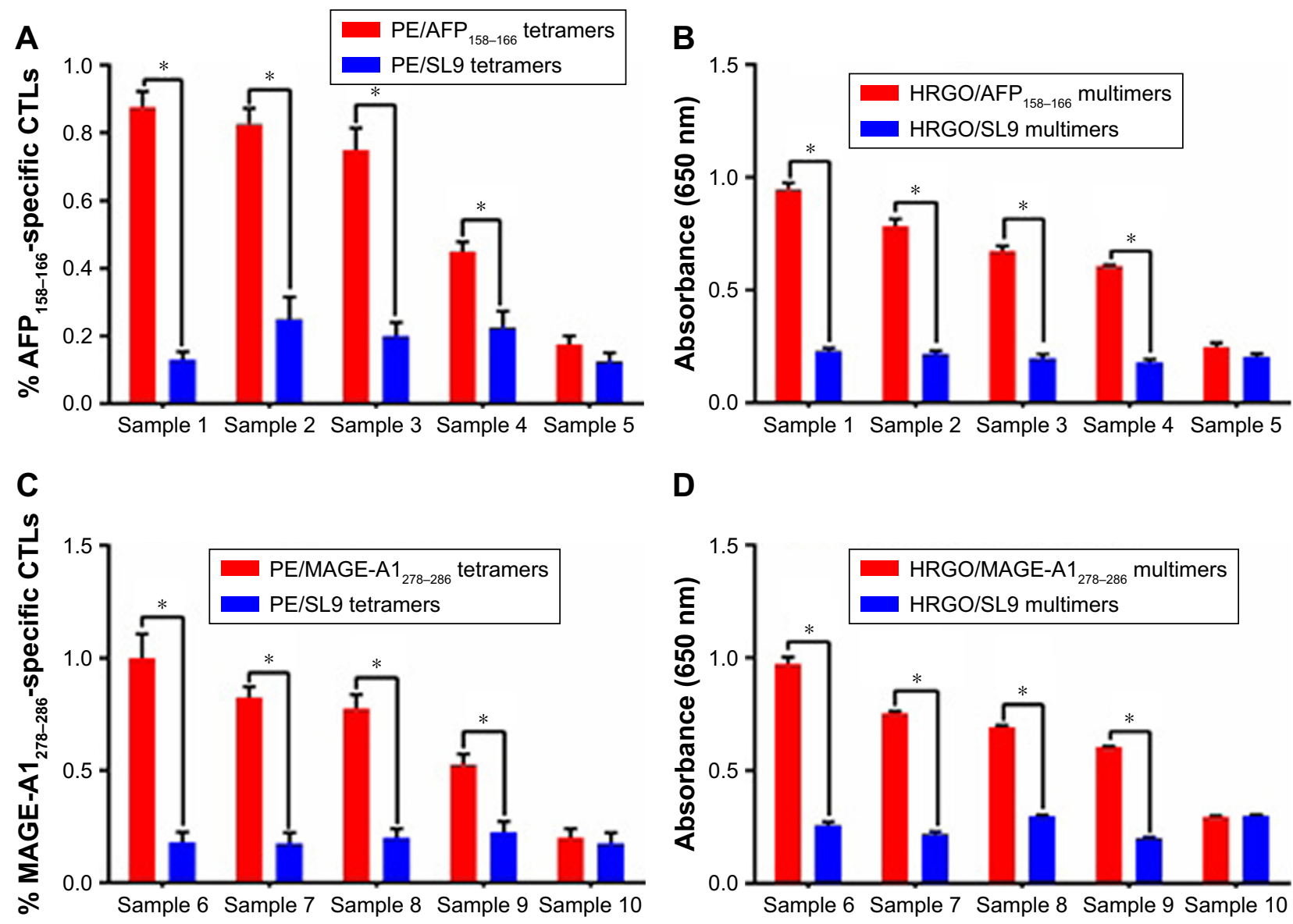

Figure 8 Statistical comparison of the frequency of hepatocellular carcinoma-specific T-cells from the ten clinical blood samples detected by the HRGO/MHC-peptide multimer method compared with the PE/MHC-peptide tetramer method.

Notes: Every clinical blood sample was tested four times. Statistical analysis of the detection of AFP $158-166^{-s p e c i f i c ~ T-c e l l s ~ u s i n g ~(A) ~ f l o w ~ c y t o m e t r y ~ a n d ~(B) ~ t h e ~ n o v e l ~}$ graphene-based assay $(n=4)$. Also, statistical analysis of the detection of MAGE-AI $278-286$-specific T-cells using (C) flow cytometry and (D) the novel graphene-based assay $(\mathrm{n}=4)$. Data represent mean $\pm \mathrm{SD}, * P<0.05$.

Abbreviations: CTL, cytotoxic T lymphocyte; HRGO, hemin reduced graphene oxide; MHC, major histocompatibility complex; PE, phycoerythroprotein.

Second, expensive flow instruments are not necessary. Efficient detection can be achieved simply from a microplate reader. In addition, the peroxidase substrate can be oxidized to cause color change and is stable compared with the commonly used HRP enzyme. ${ }^{27,28}$ The multimeric structure makes it compatible with $\mathrm{T}$ cell receptors which have more affinity and are more stable than the tetramer. ${ }^{29,30}$ Last but not least, as the new method allows us to detect batch of samples, a large number of samples can be processed in a short time, while flow cytometry can only detect samples one by one.

The ratio of graphene to hemin needed to be optimized to obtain efficient $\mathrm{HRGO} / \mathrm{pMHC}$ multimers. In our study, different ratios of graphene and hemin $(1: 1,1: 3,1: 5,1: 8$, and 1:10) were investigated, while the highest load efficiency of hemin on graphene was achieved at the ratio of 1:5. Further increasing the amount of hemin did not enhance the load efficiency. Ensuring good dispersion of graphene in aqueous solution is also the key to this study. ${ }^{31}$ The particle size evalu- ation showed that GO, HRGO, and HRGO/pMHC multimers all possessed their sizes at nanoscale, indicating good dispersion. The single zeta potential peak also demonstrated that negligible impurities existed in the substances.

T-cell analysis by flow cytometry is based on the detection of the frequency of CTLs in the whole cell sample; however, the HRGO/pMHC multimer technique is based on the overall number of CTLs in cell samples rather than the percentage. The signal could be detected even if a small amount of CTLs were present. Therefore, we argued that the detection efficiency of the HRGO/pMHC multimer based assay was more sensitive in the case of a low percentage of specific T-cells. When the number of T-cells was low $\left(<5 \times 10^{3}\right)$, flow cytometry was unable to detect the PE/pMHC tetramer-labeled specific T-cells. However, there was still a detection signal at $2 \times 10^{3}$ of T-cells when $\mathrm{AFP}_{158-166}$-specific T-cells were labeled with $\mathrm{HRGO/pMHC}$ multimers. When the number of specific T-cells was extremely high, flow cytometry might 
show effective detection on the condition that the overall number of T-cells was sufficient.

In this study, to investigate the potency of $\mathrm{HRGO} / \mathrm{pMHC}$ multimers for detecting hepatocellular carcinoma-specific T-cells in real clinical blood samples, eight cases of hepatocellular carcinoma and two healthy persons were enrolled. The sensitivity of specific T-cell detection with $\mathrm{HRGO} / \mathrm{pMHC}$ multimers was relatively high, since the absorption peaks of hepatocellular carcinoma-specific T-cells from the eight cases were higher than the control groups (Figure 7B and D). For the two healthy samples, both the results of flow cytometry and the absorption spectra method showed similar low signals. A falsepositive result appeared with neither method, so the specificity of the novel assay was as good as that of flow cytometry.

We selected the $\mathrm{AFP}_{158-166}$ and MAGE-A1 ${ }_{278-286}$ antigenic peptide epitopes as they have high expression in hepatocellular carcinoma patients. Both are highly expressed in the development and progression of hepatocellular carcinoma and the adoptive immunotherapy for hepatocellular carcinoma. ${ }^{32-34}$ In fact, the selectivity test was performed with not only the CTLs mentioned in the article, but also the CTLs generated by peptide from human hepatitis B core, $\mathrm{HIV}$, human papilloma virus, and melanoma peptides, as well as influenza matrix peptide. The new method may need more detection of antigen peptide-induced CTL before clinical trials. Here, we just selected hepatocellular carcinomaspecific T-cells as a model. For future studies, however, we might select more antigenic peptide epitopes for analysis.

Recently, the technologies of graphene-based nanomaterials and MHC tetramers are promising tools in biomedical applications and for the detection of antigen peptide-specific $\mathrm{CD}^{+}{ }^{+}$-cells. ${ }^{35,36}$ In this study, based on the graphene and tetramer technologies, $\mathrm{HRGO} / \mathrm{pMHC}$ multimers were shown to selectively and sensitively detect the hepatocellular carcinoma-specific T-cells in a short time frame. This methodology has unique advantages in the field of medical immunology and will be very useful in the study of T-cellrelated immune responses. . $^{37,38}$

\section{Acknowledgments}

This work is supported by the Medicine and Health Research Foundation of Zhejiang Province (2018KY147, 2016DTB001), National Natural Science Foundation of China (81772664, 81501824), Fund for Integration of Cloud Computing and Big data, Innovation of Science and Education (2017A11036), Traditional Chinese Medicine Scientific Research Foundation of Zhejiang Province (2018ZY001, 2015ZZ001, 2014ZQ005), Natural Science Foundation of Zhejiang Province
(LY15C090004, LQ17H160017), and the Health Science and Technology Project of Hangzhou (2018B072), Hangzhou Bureau of Science and Technology (20140633B67).

\section{Disclosure}

The authors report no conflicts of interest in this work.

\section{References}

1. Betts MR, Nason MC, West SM, et al. HIV nonprogressors preferentially maintain highly functional HIV-specific CD8+ T cells. Blood. 2006;107(12):4781-4789.

2. Bhat M, Ghali P, Deschenes M, Wong P. Prevention and management of chronic hepatitis B. Int J Prev Med. 2014;5(Suppl 3):S200-S207.

3. Yang Z, Xu M, Jia Z, et al. A novel antigen delivery system induces strong humoral and CTL immune responses. Biomaterials. 2017; 134:51-63.

4. Zvi A, Rotem S, Zauberman A, et al. Novel CTL epitopes identified through a $Y$. pestis proteome-wide analysis in the search for vaccine candidates against plague. Vaccine. 2017;35(44):5995-6006.

5. Liu Q, Zheng Y, Yu Y, Tan Q, Huang X. Identification of HLA-A*0201restricted CD8+ T-cell epitope $\mathrm{C}_{64-72}$ from hepatitis $\mathrm{B}$ virus core protein. Int Immunopharmacol. 2012;13(2):141-147.

6. Meidenbauer N, Hoffmann TK, Donnenberg AD. Direct visualization of antigen-specific T cells using peptide-MHC-class I tetrameric complexes. Methods. 2003;31(2):160-171.

7. Erskine CL, Henle AM, Knutson KL. Determining optimal cytotoxic activity of human Her2neu specific CD8 T cells by comparing the Cr51 release assay to the xCELLigence system. J Vis Exp. 2012; 66(66):e3683.

8. Wu C, Liu J, Zhang P, et al. A recognition-before-labeling strategy for sensitive detection of lung cancer cells with a quantum dot-aptamer complex. Analyst. 2015;140(17):6100-6107.

9. Zhao X, Xu L, Sun M, et al. Gold-Quantum dot core-satellite assemblies for lighting up microRNA in vitro and in vivo. Small. 2016;12(34): 4662-4668.

10. Dolton G, Lissina A, Skowera A, et al. Comparison of peptide--major histocompatibility complex tetramers and dextramers for the identification of antigen-specific T cells. Clin Exp Immunol. 2014;177(1): 47-63.

11. Beloki L, Ciáurriz M, Mansilla C, etal. The abrogation of TCR-independent interactions with human serum ensures a selective capture of therapeutic virus-specific CD8+ T-cells by multimer technology in adoptive immunotherapy. J Immunol Methods. 2013;396(1-2):168-172.

12. Batard P, Peterson DA, Devêvre E, et al. Dextramers: new generation of fluorescent MHC class I/peptide multimers for visualization of antigenspecific CD8+ T cells. J Immunol Methods. 2006;310(1-2):136-148.

13. Kang BH, Min HS, Lee YJ, et al. Analyses of the TCR repertoire of MHC class II-restricted innate CD4+ T cells. Exp Mol Med. 2015;47:e154.

14. Abdullah-Al-Nahain, Lee JE, In I, et al. Target delivery and cell imaging using hyaluronic acid-functionalized graphene quantum dots. Mol Pharm. 2013;10(10):3736-3744.

15. Ameri SK, Singh PK, Sonkusale S. Utilization of graphene electrode in transparent microwell arrays for high throughput cell trapping and lysis. Biosens Bioelectron. 2014;61:625-630.

16. Batra K, Nayak S, Behura SK, Jani O. Optimizing performance parameters of chemically-derived graphene/p-Si heterojunction solar cell. J Nanosci Nanotechnol. 2015;15(7):4877-4882.

17. Casaluci S, Gemmi M, Pellegrini V, di Carlo A, Bonaccorso F. Graphene-based large area dye-sensitized solar cell modules. Nanoscale. 2016;8(9):5368-5378.

18. Chen YW, Liu TY, Chen PJ, Chang PH, Chen SY. A High-sensitivity and low-power theranostic nanosystem for cell SERS imaging and selectively photothermal therapy using anti-EGFR-conjugated reduced graphene oxide/mesoporous silica/AuNPs nanosheets. Small. 2016;12(11):1458-1468. 
19. Cha C, Shin SR, Gao X, et al. Controlling mechanical properties of cell-laden hydrogels by covalent incorporation of graphene oxide. Small. 2014;10(3):514-523.

20. Begum P, Fugetsu B. Induction of cell death by graphene in Arabidopsis thaliana (Columbia ecotype) T87 cell suspensions. J Hazard Mater. 2013;260:1032-1041.

21. Behura SK, Mahala P, Nayak S, et al. Fabrication of bi-layer graphene and theoretical simulation for its possible application in thin film solar cell. J Nanosci Nanotechnol. 2014;14(4):3022-3027.

22. Ling Y, Chen LX, Dong JX, Li NB, Luo HQ. A simple and rapid method for direct determination of $\mathrm{Al}$ (III) based on the enhanced resonance Rayleigh scattering of hemin-functionalized graphene-Al(III) system. Spectrochim Acta A Mol Biomol Spectrosc. 2016;156:22-27.

23. Lv X, Weng J. Ternary composite of hemin, gold nanoparticles and graphene for highly efficient decomposition of hydrogen peroxide. Sci Rep. 2013;3:3285.

24. Guo Y, Deng L, Li J, et al. Hemin-graphene hybrid nanosheets with intrinsic peroxidase-like activity for label-free colorimetric detection of single-nucleotide polymorphism. ACS Nano. 2011;5(2):1282-1290.

25. Gu CJ, Kong FY, Chen ZD, et al. Reduced graphene oxide-Hemin-Au nanohybrids: facile one-pot synthesis and enhanced electrocatalytic activity towards the reduction of hydrogen peroxide. Biosens Bioelectron. 2016;78:300-307.

26. Cole DK, Pumphrey NJ, Boulter JM, et al. Human TCR-binding affinity is governed by MHC class restriction. J Immunol. 2007;178(9): 5727-5734.

27. Oprea R, Peteu SF, Subramanian P, et al. Peroxynitrite activity of hemin-functionalized reduced graphene oxide. Analyst. 2013;138(15): 4345-4352.

28. Wei W, Zhang DM, Yin LH, Pu YP, Liu SQ. Colorimetric detection of DNA damage by using hemin-graphene nanocomposites. Spectrochim Acta A Mol Biomol Spectrosc. 2013;106:163-169.

29. Casalegno-Garduño R, Schmitt A, Yao J, et al. Multimer technologies for detection and adoptive transfer of antigen-specific T cells. Cancer Immunol Immunother. 2010;59(2):195-202.
30. Dolton G, Tungatt K, Lloyd A, et al. More tricks with tetramers: a practical guide to staining T cells with peptide-MHC multimers. Immunology. 2015;146(1):11-22.

31. Zhou H, Zhang YY, Liu J, Xu JJ, Chen HY. Efficient quenching of electrochemiluminescence from K-doped graphene-CdS:Eu NCs by G-quadruplex-hemin and target recycling-assisted amplification for ultrasensitive DNA biosensing. Chem Commun (Camb). 2013;49(22): 2246-2248.

32. Liu H, Xu Y, Xiang J, et al. Targeting alpha-fetoprotein (AFP)-MHC complex with CAR T-cell therapy for liver cancer. Clin Cancer Res. 2017;23(2):478-488.

33. Mongkhoune S, Xie YA, Wang YQ, et al. A constructed HLA-A2restricted pMAGE-A1(278-286) tetramer detects specific cytotoxic T lymphocytes in tumour tissues in situ. J Int Med Res. 2013;41(6): 1811-1824.

34. Sun L, Guo H, Jiang R, et al. Engineered cytotoxic T lymphocytes with AFP-specific TCR gene for adoptive immunotherapy in hepatocellular carcinoma. Tumour Biol. 2016;37(1):799-806.

35. Wang XC, Pang H, Xu X, et al. Streptamer versus tetramer-based selection of functional cytomegalovirus-specific T cells. J Formos Med Assoc. 2013;112(6):338-345.

36. Tungatt K, Bianchi V, Crowther MD, et al. Antibody stabilization of peptide-MHC multimers reveals functional T cells bearing extremely low-affinity TCRs. J Immunol. 2015;194(1):463-474.

37. Chen H, Zhang J, Gao Y, et al. Sensitive cell apoptosis assay based on caspase-3 activity detection with graphene oxide-assisted electrochemical signal amplification. Biosens Bioelectron. 2015;68:777-782.

38. Chen L, Zhou Y, Tu W, et al. Enhanced photovoltaic performance of a dye-sensitized solar cell using graphene- $\mathrm{TiO} 2$ photoanode prepared by a novel in situ simultaneous reduction-hydrolysis technique. Nanoscale. 2013;5(8):3481-3485. 


\section{Supplementary material}

A

\begin{tabular}{|l|l|l|l|l|l|}
\hline TMB $(\mu \mathrm{L})$ & 100 & 100 & 100 & 100 & 100 \\
\hline $\mathrm{H}_{2} \mathrm{O}_{2}(\mu \mathrm{L})$ & 1.6 & 1.3 & 1 & 0.5 & 0.2 \\
\hline Time (minutes) & 30 & 30 & 30 & 30 & 30 \\
\hline Absorbance (au) & 0.936 & 0.940 & 0.942 & 0.741 & 0.517 \\
\hline
\end{tabular}

B

\begin{tabular}{|l|l|l|l|l|l|}
\hline TMB $(\mu \mathrm{L})$ & 140 & 120 & 100 & 80 & 60 \\
\hline $\mathrm{H}_{2} \mathrm{O}_{2}(\mu \mathrm{L})$ & 1 & 1 & 1 & 1 & 1 \\
\hline Time (minutes) & 30 & 30 & 30 & 30 & 30 \\
\hline Absorbance $(\mathrm{au})$ & 0.920 & 0.922 & 0.942 & 0.862 & 0.647 \\
\hline
\end{tabular}

C

\begin{tabular}{|l|l|l|l|l|l|}
\hline TMB $(\mu \mathrm{L})$ & 100 & 100 & 100 & 100 & 100 \\
\hline $\mathrm{H}_{2} \mathrm{O}_{2}(\mu \mathrm{L})$ & 1 & 1 & 1 & 1 & 1 \\
\hline Time (minutes) & 40 & 35 & 30 & 25 & 20 \\
\hline Absorbance (au) & 0.941 & 0.942 & 0.942 & 0.912 & 0.753 \\
\hline
\end{tabular}

Figure SI Optimized data for experimental conditions of TMB calorimetric reaction.

Notes: Optimized data of $(\mathbf{A}) \mathrm{TMB},(\mathbf{B}) \mathrm{H}_{2} \mathrm{O}_{2}$, and $(\mathbf{C})$ colorimetric reaction time. For all the experiments, the same volume of $\mathrm{HRGO}(\mathrm{I} 0 \mu \mathrm{g} / \mathrm{mL}) \mathrm{was}$ added. As shown in the figure, the optimal catalytic reaction needed I00 $\mu \mathrm{L} \mathrm{TMB}$ substrate, I $\mu \mathrm{L} \mathrm{H}_{2} \mathrm{O}_{2}(500 \mathrm{mM})$, and incubation for 30 minutes. The value of the absorbance is $0.942 \mathrm{OD}$. Abbreviations: HRGO, hemin reduced graphene oxide; TMB, tetramethylbenzidine.

\section{Publish your work in this journal}

The International Journal of Nanomedicine is an international, peerreviewed journal focusing on the application of nanotechnology in diagnostics, therapeutics, and drug delivery systems throughout the biomedical field. This journal is indexed on PubMed Central, MedLine, CAS, SciSearch ${ }^{\circledR}$, Current Contents ${ }^{\circledR} /$ Clinical Medicine,
Journal Citation Reports/Science Edition, EMBase, Scopus and the Elsevier Bibliographic databases. The manuscript management system is completely online and includes a very quick and fair peer-review system, which is all easy to use. Visit http://www.dovepress.com/ testimonials.php to read real quotes from published authors. 